\begin{tabular}{|c|c|c|}
\hline & Int.J.Curr.Microbiol.App.Sci (2016) 5(12): 772-776 & \multirow{2}{*}{ 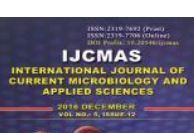 } \\
\hline & International Journal of Current Microbiology and Applied Sciences & \\
\hline & ISSN: 2319-7706 Volume 5 Number 12 (2016) pp. 772-776 & \\
\hline $\begin{array}{l}\text { EXCELLENT } \\
\text { PUBLISHERS }\end{array}$ & & \\
\hline
\end{tabular}

\title{
DMC (Designated Microscopic Centers) Enhanced with Light Emitting Diode (LED) Back up from RNTCP Cell - A Pilot Study Conducted in Dharmapuri District of Tamil Nadu, India
}

\author{
T. Sabeetha, Gowri Veligandla* and Stalin \\ Department of Microbiology, Govt. Dharmapuri Medical College, Dharmapuri, Tamilnadu, India \\ *Corresponding author:
}

\section{A B S T R A C T}

Keywords

ATT (Anti

tuberculous

therapy),

designated

microscopic

centers (DMC).

Article Info

Accepted:

28 November 2016

Available Online:

10 December 2016

\begin{abstract}
In the annual global burden of 8.6 million TB cases, India accounted for $20 \%$. In the last two quarters of the year 2012, the RNTCP cell at Dharmapuri Medical College had recorded a twofold increase in slide positivity rate with use of LED microscope, which was more than the peripheral designated microscopic centers (DMC). This study was planned to increase the efficiency of the DMCs by early detection and intiation of ATT (Anti tuberculous therapy) in new cases, to recheck them for quality assurance and thereby increase the access of RNTCP service to periphery areas. Early morning sputum samples from 488 suspected cases of tuberculosis were collected from the DMCs in the three Tuberculin Units. The smears were screened only by $\mathrm{ZN}$ staining at the DMCs ,but screened simultaneously by ZN staining and LED at the RNTCP cell in the tertiary care centre. The present study showed smear positivity by both methods was nearly the same. The false negativity was considerably lower by $1 \%$ in LED when compared with $\mathrm{ZN}$ microscopy. The objective to assess the performance of laboratory at the DMC was done and was satisfactory. 6 new cases missed at the DMC were picked up by LED at RNTCP Cell and after confirmation, treatment was initiated without delay. In the present study $(21 / 488) 4 \%$ of the sample size were children $(0-11 \mathrm{yr})$ age group. Hence the present study highlighted the need to identify the incidence of pediatric TB in our local population and suggested further research.
\end{abstract}

\section{Introduction}

India has one of the highest tuberculosis burdens globally. The Indian TB cases accounts for $20 \%$ of the 8.6 million global burdens occurring annually as per TB India 2006 and WHO Global tuberculosis report in 2013. However few studies have focused on TB in young children, a vulnerable population, where lack of early diagnosis results in poor outcomes. The burden of childhood $\mathrm{TB}$ in India is not known, regional data from the $\mathrm{WHO}$ indicate the sputum microscopy smear-positive TB in children (<14years) accounts for $0.6 \%$ to $3.6 \%$ of all reported cases. This was reported by John et al., (2013).
RNTCP relies mainly on quality sputum microscopy for diagnosis, categorization of patients and assessment of treatment progress. The credibility, success and sustainability of the RNTCP depends on the strength of the laboratory network. Poor quality microscopy service fails to detect persons with infectious TB, who will be the source of infection to the community.

According to RNTCP, the patients with both smear negative sputum specimens will be subjected to broad spectrum antibiotic treatment for 2 weeks. If the symptoms persist after two weeks, sputum smear 
microscopy by Ziehl Neelson's technique is repeated. If it is positive, anti-tuberculosis treatment is started. So there was a two week delay when only Ziehl Neelson's technique was done to screen for tuberculosis. So our study was planned to avoid the two week delay by simultaneous microscopic examination of the smear by both $\mathrm{ZN}$ and LED. So the present study was planned to augment case finding at the DMC by quality smear microscopy at the RNTCP cell. This study also was designed to serve as an external quality assurance (EQA) method to assess whether the DMCs have an acceptable level of performance. This could be done by doing blind rechecking of the smear at the RNTCP cell within the Tertiary care centre.

\section{Materials and Methodology}

This is a cross sectional study planned with a sample size of 500 new suspected cases of tuberculosis, who had presented to one of the DMCs in the 3 selected tuberculin districts.

\section{Sampling: Cluster}

Sample size: 500 new suspected cases

Selection of samples: one early morning sputum sample from suspected case of tuberculosis at the DMCS

\section{Inclusion criteria}

New cases suspected to have TB, which includes

1 AFB smear positive slide

2. AFB smear negative slide

Exclusion criteria

1. Default cases of TB

\section{Sample source}

Dharmapuri TU

Palayamputhur TU

B. Mallapuram TU

Two sets of smears were made at the DMCs, out of which one was retained there to do $\mathrm{ZN}$ staining alone. The other set was sent to the RNTCP cell at the tertiary care centre, for simultaneous microscopic examination of the smear by both $\mathrm{ZN}$ and LED

\section{Results and Discussion}

In the current study early morning sputum sample from 488 suspected cases of tuberculosis were collected from the DMCs in the three Tuberculin Units palayamputhur, Dharmapuri and B.Mallapuram.

Table I shows the correlation between the conventional $\mathrm{ZN}$ method and the LED method. The ZN smear positivity rate at the DMC and the smear positivity rate at the RNTCP cell with LED was $6.15 \%(30 / 488)$ and $6.97 \%(34 / 488)$ respectively. This shows the smear positivity for both the methods was nearly the same. While certain studies in India like Lord Wazim Reza et al., (2013) and certain studies abroad $\mathrm{Z}$ Khatun et al (2011) suggest that LED method of fluorescence microscopy is better than $\mathrm{ZN}$ staining for diagnosis of pulmonary tuberculosis, in the present study the smear positivity detected by both the methods were almost same. So further studies with a larger sample size may be needed.

Table II shows the direct comparison of smear examination result by $\mathrm{ZN}$ staining at DMC and LED at the RNTCP cell, GDMC. Out of the 488 smears total number of smear positives found in both LED and DMC were 28. The total number of smear positives by 
LED alone and $\mathrm{ZN}$ staining at DMC alone were 34 and 28 respectively. The total number of smear negative for AFB by both $\mathrm{ZN}$ staining and LED were found to be 452 . About 6 smears which were negative by $\mathrm{ZN}$ staining at DMC were smear positive by LED at the RNTCP cell, Govt. Dharmapuri Medical College, Dharmapuri. 2 smears which were positive by ZN staining at DMC were found to be negative by LED.

Table.1 Result of smear examination result by ZN staining (DMC) and

LED (RNTCP cell GDMC)

\begin{tabular}{|c|c|c|}
\hline & ZN staining (DMC) & $\begin{array}{c}\text { LED staining (RNTCP } \\
\text { cell GDMC) }\end{array}$ \\
\hline Negative & 458 & 454 \\
\hline Positive & 30 & 34 \\
\hline Total & \multicolumn{2}{|c|}{488} \\
\hline
\end{tabular}

Table.2 Comparison of smear examination result by ZN staining at DMC and LED at the RNTCP cell GDMC)

\begin{tabular}{|l|l|l|l|}
\hline & DMC Positive & DMC Negative & Total \\
\hline LED Positive & 28 & 6 & 34 \\
\hline LED Negative & 2 & 452 & 454 \\
\hline Total & 30 & 458 & 488 \\
\hline
\end{tabular}

Table.3 Comparison of ZN staining at DMC and LED at the RNTCP cell ( GDMC) as a diagnostic stool for screening to detect New cases of TB by smear examination

\begin{tabular}{|l|l|l|l|l|l|l|}
\hline Parameter & Sensitivity & Specificity & $\begin{array}{l}\text { Positive } \\
\text { Predictive } \\
\text { Value }\end{array}$ & $\begin{array}{l}\text { Negative } \\
\text { Predictive } \\
\text { Value }\end{array}$ & $\begin{array}{l}\text { False } \\
\text { positivity }\end{array}$ & $\begin{array}{l}\text { False } \\
\text { Negativity }\end{array}$ \\
\hline LED & $\mathbf{9 3 . 3 \%}$ & $\mathbf{9 8 . 7 7 \%}$ & $\mathbf{8 2 . 3 5 \%}$ & $\mathbf{9 9 . 5 5 \%}$ & $\mathbf{1 . 3 1 \%}$ & $\mathbf{1 6 . 6 \%}$ \\
\hline ZN(DMC) & $\mathbf{8 2 \%}$ & $\mathbf{9 9 . 5 \%}$ & $\mathbf{9 3 . 3 \%}$ & $\mathbf{9 8 . 6 \%}$ & $\mathbf{0 . 4 4 \%}$ & $\mathbf{1 7 . 6 \%}$ \\
\hline
\end{tabular}

Table III shows the sensitivity of LED and $\mathrm{ZN}$ staining in detecting the new smear positives as $93.3 \%$ and $82 \%$ respectively. Though studies by Solomon et al., (2015), Bonnet et al., (2011) and Minion et al., (2009) suggest that LED fluorescence microscopy is $10 \%$ more sensitive to $\mathrm{ZN}$ microscopy for detecting new smear positives, the present study did not show a big difference. The specificity of LED and $\mathrm{ZN}$ staining was found to be $98.77 \%$ and $99.5 \%$ respectively. The false negativity was considerably lower by $1 \%$ in LED when compared with ZN microscopy. This was one of objectives of the present study. Though the percentage of difference of false negativity between $\mathrm{ZN}$ microscopy and LED was not very significant, it suggests that further studies in this field is mandatory with culture as the gold standard with a larger sample size.

However the other objectives of the present study such as to assess the performance of 
laboratory at the DMC was done and it was found to be satisfactory. Only 6 out of 488 pairs were missed by the DMC. But 28 were identified as positive which correlated with LED. These 6 patients who were missed by $\mathrm{ZN}$ staining at the DMC were picked up by LED and after confirmation were put on ATT. Hence Treatment was initiated without delay in these 6 patients though they were smear negative by ZN staining at the DMC. This was also one of objectives of the present study.

In the present study 21 samples out of 488 were received from children $(0-11 \mathrm{yr})$ age group. This constituted about $4 \%$ of the sample size and this incidence of $4 \%$ correlates almost with the (0.6-3.6\%) WHO report on 2009 and in a study by John et al., (2013).

In conclusion, the present study was helpful in assessing the efficiency of the DMC. It also suggests that the new smear positive case detection in the DMC (Designated Microscopic Centers) can be enhanced with Light Emitting Diode (LED) back up from RNTCP cell to aid in early diagnosis and initiation of ATT, which are the main goals of RNTCP. This study suggests that further research in a larger study population is essential to detect the false negativity with both the methods of diagnosis. The proportion of pediatric TB cases showed an increasing trend from $5.6 \%$ in 2005 to $7 \%$ in 2011, as published in the Tuberculosis India (2012). This study highlights that further research is mandatory to detect the incidence of TB in the pediatric age group in our local population.

\section{Acknowledgement}

Sincere word of thanks to the District Tuberculosis Officer, Dharmapuri District, who had extended her full support for the logistics in the study and (Operational Research Cell of the Zonal Task Force for Tuberculosis, Chennai) for funding the study.

\section{References}

Bonnet, M. et al., 2011. Performance of LED-based fluorescence microscopy to diagnose tuberculosis in a peripheral health centre in Nairobi. PLoS One, 6(2): p. e17214.

Central TB Division. 2012. Tuberculosis India 2012. Annual Report of the Revised National Tuberculosis Control Programme, Directorate of General Health Services, Ministry of Health and Family Welfare, Government of India.

Global tuberculosis control-epidemiology, strategy, financing. WHO Report 2009.

http://www.who.int/tb/publications/glo bal_report/2009/en/index.html. 31 August 2009

John, T.J. et al., 2013. "50 years if tuberculosis control in India: progress, pitfalls and the way forward," Indian Pediatrics, vol.50, no.1, pp. 93-98.

Khatun, Z., et al., 2011. Light Emitting Diode (LED) Fluorescent Microscopy: Milestone in the Detection of Paucibacillary Mycobacterium in Case of Pulmonary Tuberculosis. Bangladesh Med. J., Vol. 40 No.1.

Lord Wasim Reza. et al., 2013. LEDFluorescence Microscopy for Diagnosis of Pulmonary Tuberculosis under Programmatic Conditions in India. PLos One, 8(10): e75566.

Minion, J., et al., 2009. Light-emitting diode technologies for TB diagnosis: what is on the market? Expert Rev. Med. Devices, 6(4): pp.341-345.

Solomon, et al. 2015. Comparative Analysis of Performance of PREVI Fluo TB 
Method by Using LED-Microscopy. J. Med. Microb. Diagn., 4: 2.

TB India. 2006. RNTCP status report-DOTS for all: all for DOTS, http://tbcindia.nic.in/pdfs/TB\%20India \%202006.pdf.

WHO Global tuberculosis report. 2013. http://www.who.int/tb/publications/glo bal_report/gtbr13_executive_summary .pdf.

\section{How to cite this article:}

Sabeetha, T., Gowri Veligandla and Stalin. 2016. DMC (Designated Microscopic Centers) Enhanced with Light Emitting Diode (LED) Back up from RNTCP Cell - A Pilot Study Conducted in Dharmapuri District of Tamil Nadu, India. Int.J.Curr.Microbiol.App.Sci. 5(12): 772-776. doi: http://dx.doi.org/10.20546/ijcmas.2016.512.088 